\title{
Fragile States Index Considering Climate Factors
}

\author{
Geng-Jian Zhou ${ }^{1}$, Qiao-Xu Qin ${ }^{1}$, Wei-Zhou Lin ${ }^{3}$ \& Yuan-Biao Zhang ${ }^{1,2}$ \\ ${ }^{1}$ Innovation Practice Base of Mathematical Modeling, Electrical and Information College of Jinan University, \\ Zhuhai, China \\ ${ }^{2}$ Key Laboratory of Product Packaging and Logistics of Guangdong Higher Education Institutes, Jinan \\ University, Zhuhai, China \\ ${ }^{3}$ Electrical and Information College of Jinan University, Zhuhai, China \\ Correspondence: Yuan-Biao Zhang, Innovation Practice Base of Mathematical Modeling, Electrical and \\ Information College of Jinan University, Zhuhai, China.
}

Received: July 17, 2018 Accepted: August 12, 2018 Online Published: August 21, 2018

doi:10.5539/jms.v8n3p74 URL: https://doi.org/10.5539/jms.v8n3p74

\begin{abstract}
Over the past few decades, the Earth's climate has undergone conspicuous changes, some of which have a profound impact on social and governmental systems. The purpose of this paper is to establish a model for measuring national fragile and the impact of climate change on a country. For this purpose, we first define the Fragile States Index (FSI) to measure the fragility of a country based on population, crime rate and education, which are the three aspects that most countries or regions will focus on. Second, we use the FSI to illustrate how climate change affects the Democratic Republic of the Congo. Third, we analyze the definitive indicators of Indonesia and predict the changes of FSI. Finally, the effects of each intervention policy were obtained by analyzing Indonesia's intervention policy on environmental change. To provide ideas for intervention on climate change.
\end{abstract}

Keywords: Fragile States Index, climate change, impact factor

\section{Introduction}

\subsection{Introduce the Problem}

Through the data and research in recent years, the Climate Change will directly or indirectly affect a country or region. The main manifestations are slow economic growth and regional conflicts, etc. The Intergovernmental Panel on Climate Change suggests that the net damage costs of climate change are likely to alter the way humans live, and may have the potential to cause the weakening and breakdown of social and governmental structures. Being a fragile state can increase the people's resistance to sudden changes in the climate. Non-sustainable environmental practices, migration, and resource shortages are all likely to aggravate states with weak governance (Schwartz \& Randall, 2004; Theisen, Gleditsch, \& Buhaug, 2013). There is evidence that it can trigger violent conflicts when it is combined with weak governance and social divisions. Therefore, the purpose of this study is to propose a perspective to measure the instability of a country or region in order to make timely adjustment and governance

\subsection{Explore Importance of the Problem}

The effects of Climate Change, to include increased droughts, shrinking glaciers, changing animal and plant ranges, and sea level rise, are already being realized and vary from region to region. A fragile state is one where the state government is not able to, or chooses not to, provide the basic essentials to its people. For the purpose of this paper "state" refers to a sovereign state or country. Once again, non-sustainable environmental practices, migration, and resource shortages, which are common in developing states, may further aggravate states with weak governance (Schwartz \& Randall, 2004; Theisen, Gleditsch \& Buhaug, 2013). Arguably, drought in both Syria and Yemen further exacerbated already fragile states. Environmental stress alone does not necessarily trigger violent conflict, but evidence suggests that it enables violent conflict when it combines with weak governance and social fragmentation. This confluence can enhance a spiral of violence, typically along latent ethnic and political divisions. Therefore, the research in this paper is of certain significance. 


\subsection{Relevant Scholarship}

History has shown that environmental instability (such as political instability and insufficient natural resources) can easily lead to regional conflicts (Krakowka, Heimel, \& Galgano, 2012). Some scholars have studied the impact of sudden climate change on U.S. national security. A combination of factors can lead to a fragile state, a fragile state has several attributes, which usually includes the central government can not provide public services, a widespread corruption and crime, a sharp economic downturn (Menkhaus, 2014). Climate change can directly affect a country's Fragile States Index (FSI), but it can also influence national fragility indicators by influencing economic, social, political and other factors. According to The Fund for Peace, Fragile Country Index (FSI) is used to assess the fragility of a country's collapse, and Generally 12 risk indicators are used to measure the FSI. These 12 indicators measure FSI from four aspects: cohesion, economy, poitical, and social. Each indicator has a score of 10, dividing countries into 4 levels: Alert (index above 90), Warning (index within 90 to 60), Calm (index within 60 to 30) and Sustainable development (index below 30).

\subsection{Research Design}

First, we need to define the Fragile States Index (FSI). This paper focuses on the impact of climate change on FSI, so the direct and indirect impacts of climate should be added to re-develop a model that describes the FSI. Then, according to the existing national classification, national data are re-substituted into the defined indicators, and a new division of fragility is obtained.

In the top 10 most vulnerable countries, choose a country. Combined with the FSI, analyze how climate change has made this country vulnerable from the government reports in this country and related research. Through the control of variables, the model is used to analyze the situation when there is no climate impact in the area and further confirm the impact of climate on the national fragility through comparison. Apply the model to a country that is not in the top 10 most vulnerable countries. From a decisive variable perspective, explain how climate change will make countries more vulnerable. With less data in the past few years, a gray forecast is used to predict when the country will become more vulnerable.

Finally, find the specific policy of the selected country. Through a comprehensive evaluation of the effects and costs of policies, it shows which interventions mitigate the risks of climate change and reduce the fragility of countries. Apply FSI to a smaller or larger scope and determine whether the indicator is still applicable and accurate. If not suitable, we need to put forward the smaller or larger scope of the applicable improvements combining with the actual situation.

\section{The Establishment and Solution of the Model}

\subsection{Establishment of the FSI Model}

FSI is used to assess the fragile of a country's collapse. Ikpe believes that fragility involves "the capacity of the state" to adapt to changing circumstances, protect citizens, absorb shocks and manage conflicts in a manner that does not resort to violence (Ikpe E, 2007). The current common method of evaluation is to measure FSI with 12 risk indicators of conflict. Taking into account the direct and indirect impacts of climate, the FSI is measured by four first-level indicators of social, political, economic and climate according to the original measurement perspective. Each first-level indicator is measured by a number of second-level indicators: 


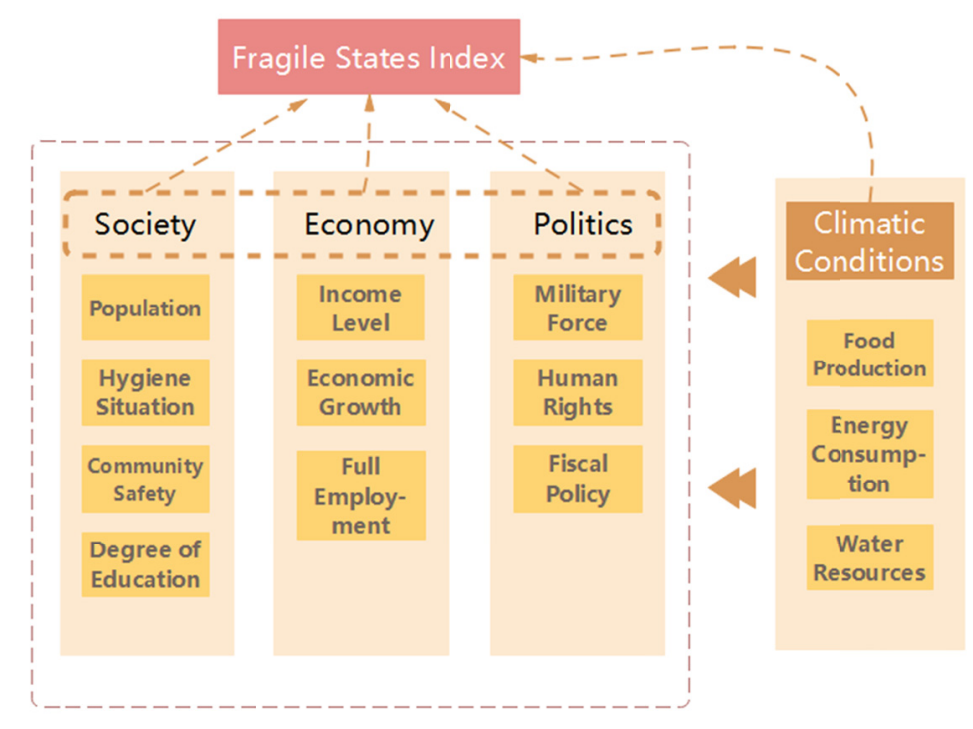

Figure 1. FSI indicator

Based on the existing FSI assessment, each aspect has a different degree of influence on the FSI, giving one weight to each indicator (the determination of weights will be done later), The specific formula is as follows:

$$
\begin{aligned}
\text { Fragile States Index } & =\beta_{1} \text { Society Index }+\beta_{2} \text { Economy Index } \\
& +\beta_{3} \text { Politics Index }+\beta_{4} \text { Climatic Conditions Index }
\end{aligned}
$$

Where $\beta_{i}$ is the weight coefficient.

In the 13 specific indicators, the score interval of each index is between $[0,1]$.

Use the following methods to convert metrics to maximum-sized indicators:

For the minimum-sized indicator: $x_{j}^{\prime}=\frac{1}{x_{j}}$

For medium-sized indicators: $x_{j}{ }^{\prime}=\left|x_{j}-x_{\text {median }}\right|$

For interval indicators: $x_{j}^{\prime}= \begin{cases}1-\frac{a_{j}-x_{j}}{c_{j}}, & x_{j}<a_{j} \\ 1 \quad, \quad a_{j} \leq x_{j} \leq b_{j} \\ 1-\frac{x_{j}-b_{j}}{c_{j}}, & x_{j}>b_{j}\end{cases}$

The higher the final score, the less vulnerable a country is, the more stable the country is.

\subsection{The Influence of the First Level Index}

\subsubsection{Society Index}

Social index can evaluate the status of social development and predict the future social development. It is an important basis for the formulation and selection of policies by the government and the society and an important measure for the general public to understand the status quo of the society and its changes. It can reflect a country's demographics, health conditions, social security and education penetration and so on. This indicator is measured in four aspects: (1) Urban population growth rate; (2) Mortality rate (under 5 years old); (3) Intentional homicides (per 100, 000 people); (4) Government expenditure on education.

Urban population growth rate refers to the rate of population growth living in urban areas as defined by national statistical offices. The data are based on the World Bank population projections and the urbanization rate provided by the UN World Urbanization Outlook. It can be used to measure the proportion of the population who 
participate in urban planning and development. The more urban population, the higher the degree of urbanization in the country, the higher the stability. This indicator is a medium-sized indicator.

Health conditions explain a country's medical and health conditions; it can directly explain the stability of a country's society. In one country, when health and medical conditions are poor, the mortality rate of childhood diseases in the country will certainly be higher. Therefore, Mortality rate (under-5 years old), is used to determine the country's sanitation. This indicator is a minimum-sized indicator.

The level of community safety can be judged by the country's crime rate, which means that the community in the country is safer. This indicator is a minimum-sized indicator.

Education in a stable country should also be more universal, so that the government's expenditure on education can be used to measure the extent of education in the country. This indicator is a maximum-sized indicator.

The calculation formula is as follows:

$$
\text { Society Index }=\frac{\left(1-\left|P-P_{\text {world }}\right|\right)+(1-M r)+(1-I h)+G e}{4}
$$

Where: $P$ is the Urban population growth rate (annual \%); $P_{\text {world }}$ is the World average urban population growth rate; $M r$ is the Mortality rate, under-5 (per 1, 000 live births); $I h$ is the Intentional homicides (per 100,000 people), acres of park/1000 people. $G e$ is the Government expenditure on education, total (\% of GDP).

Economy Index

Economic indicators are the names and values that reflect socio-economic phenomena. It shows the prosperity of a country because the economy of a country hit by natural disaster or war will not prosper. This indicator measures from 3 aspects: Per capita income level, GDP growth rate and the Unemployment rate.

Per capita income is the average national income of a country over a period of time (usually one year). It is an important indicator of the economic strength of the country and the wealth of the people. The higher the per capita national income, the more prosperous the country's economy. This indicator is a maximum-sized indicator.

GDP is the core indicator of national economic accounting, but also an important indicator of a country's overall economic status. GDP is positively related to the country's economic prosperity. However, the higher GDP growth rate may cause inflation, so it is a medium-sized indicator.

Unemployment rate is the main indicator of unemployment in a country or region. From an economic point of view, the unemployment rate of $4 \%-6 \%$ value is more appropriate. It is a medium-sized indicator.

The calculation formula is as follows:

$$
\text { Economy Index }=\frac{\left(G N I / G N I_{\text {world }}\right)+G+(1-U n)}{3}
$$

Where: GNI is the GNI per capita (constant 2010 US\$); GNI world $_{\text {is }}$ the world average GNI per capita (constant 2010 US\$); $G$ is the GDP growth rate (annual \%). $U n$ is the Unemployment rate, total (\% of total labor force).

\subsubsection{Politics Index}

Political indicators can reflect the stability of a country's political situation. It is measured from 3 aspects: the Proportion of seats held by women in national parliaments; This indicator is a maximum-sized indicator. Military Force.

The Proportion of seats held by women in national parliament reflects the importance a country places on women's rights. This indicator is a maximum-sized indicator.

Tax revenue rate reflects taxpayers' level of tax exposure. It can reflect the governance idea of a country's ruling party. This indicator should be a medium-sized indicator.

Military Force can show the size of a country's overall national strength, but more stable countries and war-torn 
countries should have more armed personnel, so this indicator is not easy to judge. But on the other hand, military expenditures come from the national tax revenue, so it can be measured from tax perspective.

The calculation formula is as follows:

$$
\text { Politics Index }=\frac{W m+T r}{2}
$$

Where: $W m$ is the Proportion of seats held by women in national parliaments (\%); $T r$ is the Tax revenue (\% of GDP).

\subsubsection{Climatic Conditions}

This paper mainly studies the influence of climatic factors on FSI. According to the data, we can see that the most direct impact of climatic factors is reflected in grain yield, energy, and water resources. This measure is measured in 3 aspects: the Cereal yield; the $\mathrm{CO} 2$ emissions; the Improved water source.

The Cereal yield reflects the agricultural situation in a country. Technological progress still does not change the fact that agriculture is largely affected by the climate. Countries with a suitable climate for planting have higher grain yields. This indicator is a maximum-sized indicator.

At present, fossil fuels are still the main sources of energy in the world. The consumption of fossil fuels will certainly produce greenhouse gases, so the consumption of fossil fuels can be measured by The $\mathrm{CO} 2$ emissions. The more $\mathrm{CO} 2$ emissions, the more industrialized the country is and the more stable the country is. This indicator is a maximum-sized indicator.

The droughts or humidities are largely linked to the national water resources, and the more freshwater resources a country has, the better the country will be. This indicator is a maximum-sized indicator.

The calculation formula is as follows:

$$
\text { Cliamtic Index }=\frac{\frac{C y}{C y_{\text {world }}}+\frac{C e}{C e_{\text {world }}}+W+F a}{4}
$$

Where: $C y$ is the Cereal yield (kg per hectare); $C y_{\text {world }}$ is the world average Cereal yield (kg per hectare); $\mathrm{Ce}$ is the $\mathrm{CO} 2$ emissions (metric tons per capita); $\mathrm{Ce}_{\text {world }}$ is the world average $\mathrm{CO} 2$ emissions (metric tons per capita); $W$ is the Improved water source, rural (\% of rural population with access); $F a$ is the Forest area (\% of land area);

\subsection{Determination of Weight Coefficient}

Earlier, the total score has been proposed models and specific indicators of the evaluation method:

$$
\begin{aligned}
\text { Fragile States Index } & =\beta_{1} \text { Society Index }+\beta_{2} \text { Economy Index } \\
& +\beta_{3} \text { Politics Index }+\beta_{4} \text { Climatic Conditions Index }
\end{aligned}
$$

In this section, the Grey Relational Analysis (GRA) is used to determine the weight coefficients for each item. Grey Relational Analysis (GRA) is an effective way to analyze the correlation between various factors. The principle of determining the weight by the gray relational degree is to judge the size of the correlation coefficient by the degree of difference between the actual sequence and the reference series. To reflect the contribution of this indicator to the FSI, it is necessary to amplify this slight fluctuation, that is, to give a larger weight, where the gray correlation coefficient is used as the full weight.

The steps of GRA are as follows:

Step 1: Normalization based on classification of indicators.

The previous article has transformed all the indicators into the maximum-sized indicator, so this step will not be described.

Step 2: Choose the reference series.

The reference series consists of the best value for each indicator. Through the access to information, Finland is known throughout the year in countries with a higher degree of sustainable development (Fragile states index, 
2014). Finnish data as the series, the world average as the actual series.

Step 3: Compute grey rational coefficient $\gamma_{i j}$

The equation is:

$$
\gamma_{i j}=\frac{\Delta_{\min }+\tau \Delta_{\max }}{\Delta_{i j}+\tau \Delta_{\max }}
$$

Where $\Delta_{i j}=x_{i j}-x_{0 j}, \Delta_{\text {max }}=\max _{i} \max _{j} \Delta_{i j}, \quad \Delta_{\text {min }}=\min _{i} \min _{j} \Delta_{i j}, \quad \tau=0.5$,

Step 4: Calculate the rational grade

$$
\delta_{i}=\frac{1}{n} \sum_{i=1}^{n} \gamma_{i j}, j=1, \cdots, n
$$

Add the weight to the formula, the final evaluation model is:

$$
\begin{aligned}
\text { Fragile States Index } & =0.4467 \text { Society Index }+0.6134 \text { Economy Index } \\
& +0.5884 \text { Politics Index }+0.5822 \text { Climatic Conditions Index }
\end{aligned}
$$

\subsection{Gray Prediction}

Due to the small amount of data, it is more appropriate to use Gray Prediction in predicting future conditions. Specific steps are as follows:

Step 1: the necessary inspection and processing of the known data columns. Set the reference data for $x^{(0)}=\left(x^{(0)}(1), x^{(0)}(2), \cdots x^{(0)}(\mathrm{n})\right)$ and calculate the rank ratio of the series:

$$
\lambda(k)=\frac{x^{(0)}(k-1)}{x^{(0)}(k)}(k=2,3, \cdots, \mathrm{n})
$$

If all levels fall within the $X=\left(\mathrm{e}^{n+1}, \mathrm{e}^{n+1}\right)$ that can be covered by $\lambda(k)$, then Series $x^{(0)}$ can be used as model GM $(1,1)$ and carry out grey prediction. Otherwise, it is necessary to transform the series $x^{(0)}$ to make it fall into the range of capacitive coverage, that is, go to the appropriate constant $c$ and do translation transformation.

$y^{(0)}(k)=x^{(0)}(k)+\mathrm{c}(k=1,2, \cdots, \mathrm{n})$

The rank ratio of the sequence of $y^{(0)}=\left(y^{(0)}(1), y^{(0)}(2), \cdots y^{(0)}(\mathrm{n})\right)$ is

$$
\lambda_{y}(k)=\frac{y^{(0)}(k-1)}{y^{(0)}(k)} \in X \quad(k=2,3, \cdots, \mathrm{n})
$$

Step 2: to generate a number of columns according to the method generated by the grey prediction accumulation (AGO), we can obtain the predicted value

$$
\hat{x}^{(1)}(k+1)=\left(x^{(0)}(1)-\frac{b}{a}\right) \mathrm{e}^{-a k}+\frac{b}{a}(k=1,2, \cdots, \mathrm{n}-1) \hat{x}^{(0)}(k+1)=\hat{x}^{(1)}(k+1)-\hat{x}^{(1)}(k) \quad(k=1,2, \cdots, \mathrm{n}-1)
$$

Step 3: the residual $\mathcal{E}(k)$ is calculated:

$$
\varepsilon(k)=\frac{x^{(0)}(k)-\hat{x}^{(0)}(k)}{x^{(0)}(k)}(k=1,2, \cdots, \mathrm{n})
$$

If the residual is less than 0.2 , it can be considered to meet the general requirements, and if the residual is less than 0.1 , it is considered to be higher. Then the level ratio deviation test is carried out. First, the reference data $x^{(0)}(k-1), x^{(0)}(k)$, the calculated level ratio $\lambda_{0}(k)$, and then the development coefficient $\lambda_{0}(k)$ to find the corresponding level deviation.

$$
\rho(k)=1-\left(\frac{1-0.5 a}{1+0.5 a}\right) \lambda_{0}(k)
$$

If the ratio deviation is less than 0.2 , it is considered to meet the general requirement. If the ratio deviation is $<0.1$, it is considered to be higher.

Step 4: according to the needs of the predicted value and the actual problems in the designated area obtained by the model, the corresponding prediction is given. 


\section{Results and Discussion}

\subsection{Fragile analysis in Democratic Republic of the Congo}

The title gives the top 10 most fragile states as determined by the Fragile State Index.The 10 countries are: South Sudan, Somalia, Central African Republic, Yemen, Sudan, Syria, Democratic Republic of Congo, Chad, Afghanistan and Iraq. The Democratic Republic of Congo is chosen to analyze how climate change is actually increasing the fragility of this country.

\subsubsection{The Direct Impact of the Climate}

The Republic of the Congo is located in central Africa, rich in oil, forests, arable land, hydrology, mineral resources, and agricultural favorable climate. Due to the low population density and the natural environment, agriculture and forestry are the main livelihoods in the Republic of the Congo. The Republic of the Congo is currently included in the "Medium Human Development Category" of the 2014 Human Development Report of the United Nations Development Program.

Abundant mineral resources make the country rich in energy sources, but on the other hand, climate change poses a tremendous threat to the Republic of Congo as most people are engaged in agriculture and forestry. Such as flooding. Due to the special rains affecting human settlements, agriculture, public health and biodiversity, can cause some areas of agriculture to suffer. Coastal areas will experience increased levels of flooding and coastal erosion, while coastal aquifers will become increasingly vulnerable to salt water intrusion, reducing the area of farmland and the fragility of freshwater resources to climate change, which may result in water shortages. These aspects increase the fragility of the country.

\subsubsection{Indirect Impact of the Climate}

\subsubsection{The Impact of Climate on Society}

Republic of the Congo has diseases that are vulnerable to the effects of climatic. The country's major and second leading causes of death were media transmission and water-borne diseases respectively. Malaria is a major concern in the country because it is the leading cause of death among children and adolescents, and malaria treatment accounts for $40 \%$ of health expenditures. Hot water and floods in urban areas also provide conditions for the production of mosquitoes that can cause malaria and increase people's vulnerability to the disease. At the same time, the unemployment rate of young people is high, access to and quality of basic services remain low, especially in the areas of health, water supply, sanitation, education and energy. Urban drinking water is $75 \%$ and only $10 \%$ in rural areas. The treatment facilities infrastructure and distribution network are outdated and have not kept pace with the growing urban population.

\subsubsection{The Impact of Climate on the Economy}

In the Democratic Republic of the Congo, GDP growth has been strong over the past five years (an average of $5.8 \%$ ) and the economy is expected to continue to grow in the coming years. Economic growth has led to a decline in poverty rates, improved living standards and a decline in unemployment. However, the Democratic Republic of the Congo is dominated by agriculture and forestry, which are largely affected by climate change and whose impact on the economy in the event of a major climate change slows growth and leads the Democratic Republic of the Congo Increased fragility.

\subsubsection{The Impact of Climate on Politics}

The political situation in the Democratic Republic of the Congo is very unstable and there are frequent wars. Although the war is more likely to be caused by political discord and the influence of other armed forces, it is undeniable that there are also reasons for the resources, especially the plundering of natural resources, and the perennial hot and humid climate may also be one of the reasons for the clashes. Therefore, the impact of climate on the political situation will also lead to an increase in the vulnerability of the country.

\subsection{The Division of the Fragile Level}

The newly defined indicators should also identify whether a country is very vulnerable, fragile or stable. The identification process needs to be based on the final FSI indicator score.

This paper selects nine countries from the national ratings based on the current FSI indicators: The Kingdom of Denmark; Swiss Confederation; The Republic of Finland; The republic of South Afrcia;The Republic of Colimbia; The Republic of Turkey; Central Afrcian Republic; Democratic Republic of the Congo;Republic ofChad. The nine countries are divided into three groups, each with significant differences in fragility. Apply the data from these nine countries to the newly defined FSI indicators and calculate their changes from the 
2001-2010 decade scale as follows:

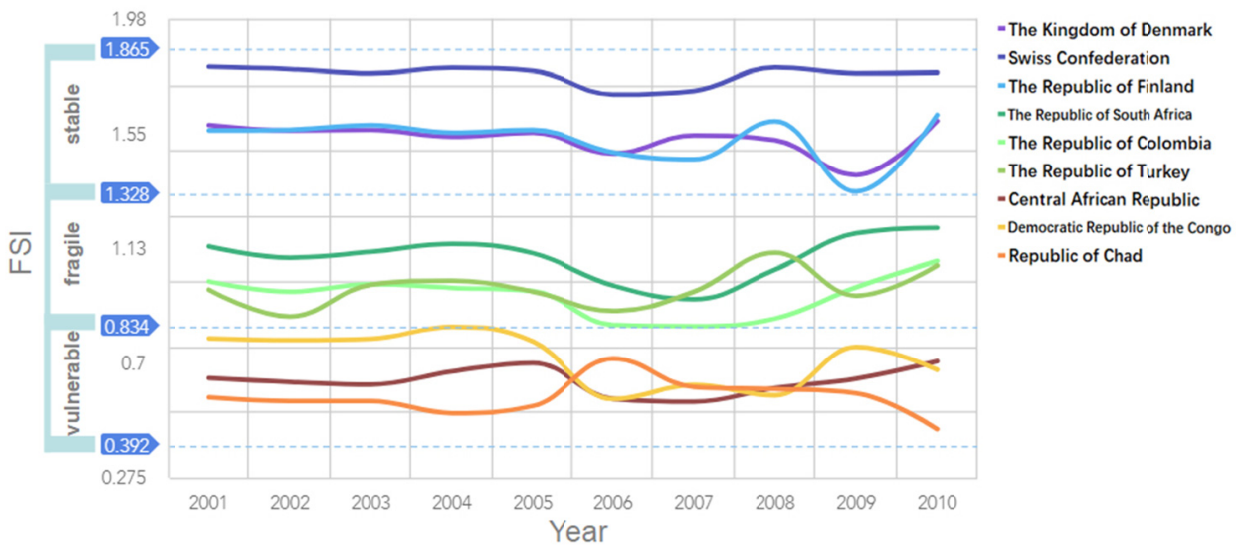

Figure 2. Indicator changes

According to the Figure 2, The Kingdom of Denmark; Swiss Confederation and The Republic of Finland score higher. Their scoring interval is between $[1.328,1.865]$. The republic of South Afrcia; The Republic of Colimbia and The Republic of Turkey Scoring average, Their scoring interval is between [0.834, 1.328]. Central Afrcian Republic; Democratic Republic of the Congo; Republic of Chad was in a poor condition with a low score, with a range of [0.392, 0.834].

According to the newly defined FSI in this paper, the state of the country with the final score of $[0.392,0.834]$ is very vulnerable; the state of the country with the final score of $[0.834,1.328]$ is fragile;the state of the country with the final score of $[1.328,1.865]$ is stable.

\subsection{Model Test}

This article selected several countries in Southeast Asia and Europe to test the indicators. These countries are selected because these countries are small in scale and close to the sea at the same time. Therefore, the fragility is more affected by the climate and can better measure the accuracy of the indicator. Comparisons of the results of the redefined formulas with those of internationally recognized countries show that the formula works better and the measured country grading is roughly in line with the expected value.

At present, the model proposed in this paper is used to define the country. The value of the attention is that there is a certain correlation between the metrics of this model, especially the impact of climate on the other three indicators. In other words, if a country's climate changes, it will not only directly affect the final rating, but also affect the rating indirectly by affecting the other three indicators. When using this model to analyze other regions or cities, it should be noted.

\subsection{Comparison without Climate Effects}

In order to use the model to illustrate the fact that in the absence of climate impacts the fragility of countries will be lower, we draw on the thinking of control variables to translate the climate data in the Democratic Republic of the Congo into desirable data and rebuild the region's score. The value of attention is that when the climate becomes optimal, the other indicators in the region will also be affected and changed, so can not simply control the variables, but should take into account the actual situation. Combined with information, when the climate data in the Democratic Republic of the Congo improved, the death rate in the area will be reduced by $4 \%$, the crime rate will be reduced by 5\%, the GDP growth rate will rise by $1.5 \%$ and the proportion of women in parliament will rise $1.2 \%$, water resources increased by $0.5 \%$ (Gourou, 2007). Using the new data again score, the data changes in the ten years from 2001 to 2010 are as follows: 


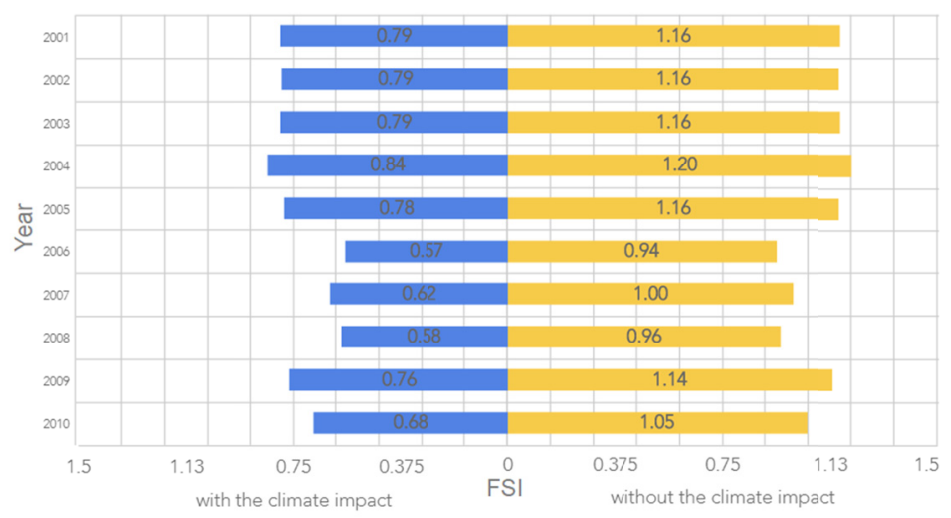

Figure 3. Comparison without climate effects

It can be seen from the above figure that when the impact of climate change on the region is not taken into consideration, the grading of each year will be somewhat improved and the vulnerability will be better. Therefore, the fact that the vulnerability of these countries will be even lower in the absence of climate impacts exists.

\subsection{Prediction in Indonesia}

In order to discuss the predictive power of the FSI indicator, in this section, apply the model to countries that are not in the top 10 most vulnerable countries to find definitive indicators. Analyze how climate change will make the country more vulnerable. At the same time define a critical point, predict when the country may become more vulnerable in the future.

The analysis below is based on data from Indonesia. The fact that Indonesia was chosen because of its geographical location led to the country being somewhat affected by the climate and conducive to analysis.

\subsubsection{Definitive Indicators}

Among the 13 FSI-specific measures, each has a different degree of impact on the FSI. Define indicators of high impact as definitive indicators.

This article counts the various data for Indonesia from 2001 to 2010 and looks at the trends through a line chart. The trend of indicators closely related to FSI must also be similar to that of FSI. Through the analysis, CO2 emissions, Cereal yield, and GDP growth rate were screened out, and the three indices are similar to the trend of FSI were taken as definitive indicators. The trend of FSI and 3 indicators are as follows:

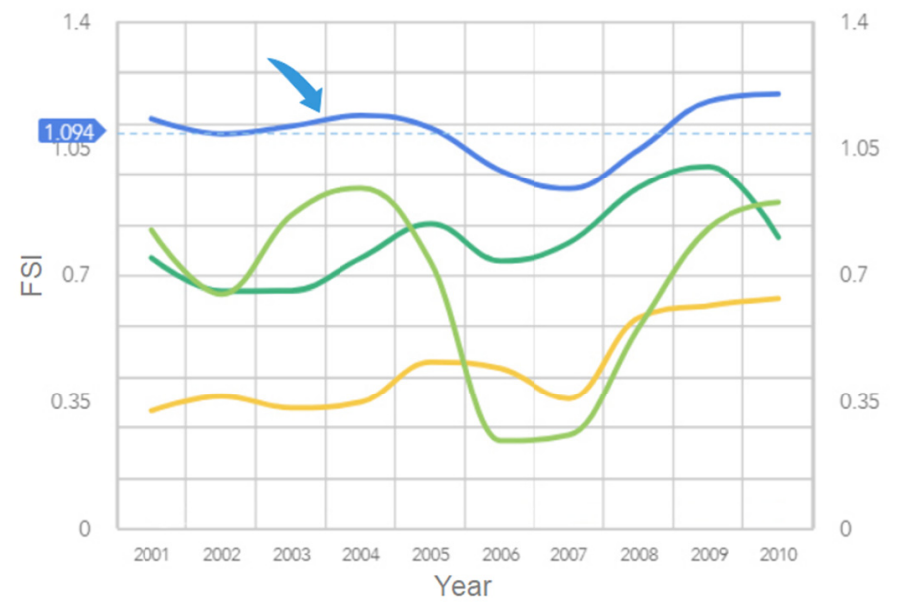

Figure 4. Indicator trends

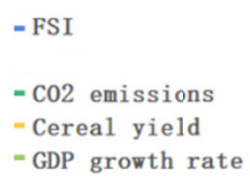


It can be seen from the Figure 4 that these three indicators are basically in line with the trend of FSI in ten years. Therefore we use these 3 indicators as definitive indicators. The following explains how these definitive indicators have made Indonesia more vulnerable.

\subsubsection{Prediction}

This part of the analysis of when the country will become more vulnerable and more vulnerable is relative to the country itself, that the FSI indicator will become even worse in the future. Taking Indonesia's average score for 2001-2010 as the tipping point will make the country more vulnerable in the future when the FSI scores below the tipping point.

Due to the small amount of data, it is more appropriate to use Gray Prediction in predicting future conditions. The forecast results are as follows:

$\mathrm{CO} 2$ emissions, Cereal yield, GDP growth rate are predicted by Gray Prediction. The other indicators are equal to the average of 2001-2010. Predict Indonesia's FSI target for 2012-2030, the forecast result is as follows:

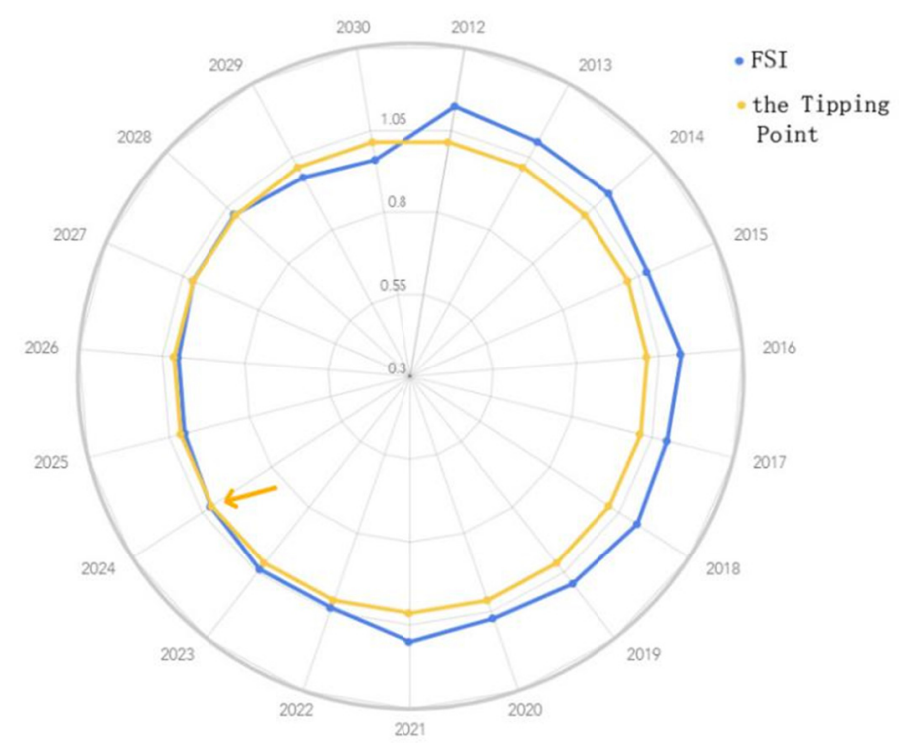

Figure 5. Forecast result

As can be seen from the radar chart, the value of the FSI indicator shows a downward trend in the future. FSI reached tipping point for the first time in 2024. For Indonesia, the country began to become more vulnerable from 2024.

\subsection{State Driven Interventions in Indonesia}

Indonesia is located between the Indian Ocean and the Pacific Ocean. Its geographical location makes the country particularly vulnerable to the effects of climate change, such as sea level rise (Bradley D,2007). In recent years, people are paying more and more attention to extreme weather events.

The frequency of extreme weather events has been increasing from the 1950s to the 1980s, and Bradley D. found that frequent extreme weather was due in large part to increases in maximum and minimum temperatures, as well as changes in rainfall patterns and wet-length. In recent years, drought has become an important factor in the crop failure in Indonesia, which causes food shortages. In addition to extreme weather, poverty and unemployment are exacerbated by the climate. The increasing number of extreme events urgently requires the immediate and effective implementation of policies. National implementation of management policies mainly from the residents livelihood, health, food security, water resources from four aspects to solve.

According to information, the policy is divided into two types of mitigation policy and adaptive policy, make a comprehensive assessment of each policy. Table 1 provides an assessment of the specific policies implemented in Indonesia: 
Table 1. Policy evaluation

\begin{tabular}{|c|c|c|c|c|c|}
\hline & \multirow{2}{*}{ Program } & \multicolumn{2}{|l|}{ Justification } & \multirow{2}{*}{ Metric } & \multirow{2}{*}{$\begin{array}{l}\text { Budget } \\
\text { (million) }\end{array}$} \\
\hline & & & Expected outcomes & & \\
\hline \multirow{3}{*}{ : } & $\begin{array}{l}\text { Climate Change Program } \\
\text { Loan }\end{array}$ & $\begin{array}{l}\text { Develop an Integrated Water Resource } \\
\text { Management Plan and a National Water } \\
\text { Council; } \\
\text { Develop a spatial land use planning } \\
\text { methodology }\end{array}$ & $\begin{array}{l}\text { Reduce greenhouse gas (forestry, } \\
\text { energy, industry) } \\
\text { Adapt to climate change (water } \\
\text { and agriculture); }\end{array}$ & $\begin{array}{l}\text { Food Production; } \\
\text { Water Resources; } \\
\text { Energy } \\
\text { Consumption }\end{array}$ & 1,300 \\
\hline & $\begin{array}{l}\text { Indonesia Climate Change } \\
\text { Center }\end{array}$ & $\begin{array}{l}\text { Provide technical expertise to assist } \\
\text { Indonesian experts and government } \\
\text { representatives to link climate change } \\
\text { policy to science }\end{array}$ & Mitigate from peat lands & $\begin{array}{l}\text { Fiscal Policy; } \\
\text { Energy } \\
\text { Consumption } \\
\text { Degree of } \\
\text { Education }\end{array}$ & 34.0 \\
\hline & $\begin{array}{l}\text { Asia Pacific Climate } \\
\text { Change Adaptation Project } \\
\text { Preparation Facility } \\
\text { (ADAPT) }\end{array}$ & $\begin{array}{l}\text { Increase access to financial resources } \\
\text { for climate change adaptation } \\
\text { investment projects;Develop regional } \\
\text { knowledge platform }\end{array}$ & $\begin{array}{l}\text { Share information and processes } \\
\text { on climate change projects and } \\
\text { funds }\end{array}$ & $\begin{array}{l}\text { Income Level; } \\
\text { Employment; } \\
\text { Economic } \\
\text { Growth; }\end{array}$ & 18.0 \\
\hline \multirow{3}{*}{ : } & $\begin{array}{l}\text { Strategic Planning and } \\
\text { Action to Strengthen } \\
\text { Climate Resilience of Rural } \\
\text { Communities in Nusa } \\
\text { Tenggara Timor province } \\
\end{array}$ & $\begin{array}{l}\text { Strengthen farmland capital } \\
\text { construction, adjust planting system, } \\
\text { breed resistant varieties and develop } \\
\text { biote- } \\
\text { chnology }\end{array}$ & $\begin{array}{l}\text { Livelihoods and sources of income } \\
\text { diversified and strengthened for } \\
\text { vulner- } \\
\text { able rural communities }\end{array}$ & $\begin{array}{l}\text { Income Level; } \\
\text { Degree of } \\
\text { Education }\end{array}$ & 59.8 \\
\hline & $\begin{array}{l}\text { Asian Cities Climate } \\
\text { Change Resilience Network }\end{array}$ & $\begin{array}{l}\text { Establish a network of cities in Asia that } \\
\text { will catalyze attention, funding and } \\
\text { action on building climate change } \\
\text { resilience }\end{array}$ & $\begin{array}{l}\text { Develop robust plans to prepare } \\
\text { for, withstand and recover from } \\
\text { the predicted impacts of climate } \\
\text { change }\end{array}$ & $\begin{array}{l}\text { Income Level; } \\
\text { Employment; } \\
\text { Degree of } \\
\text { Education }\end{array}$ & 40.0 \\
\hline & $\begin{array}{l}\text { US Support Program to the } \\
\text { Coral Triangle Initiative } \\
\text { (CTI) }\end{array}$ & $\begin{array}{l}\text { Improve the management of } \\
\text { biologically and economically } \\
\text { important coastal and marine resources } \\
\text { and associated ecosystems that support } \\
\text { livelihoods and economies in the Coral } \\
\text { Triangle }\end{array}$ & $\begin{array}{l}\text { Building climate change adaptive } \\
\text { capacity and establishing regional } \\
\text { platforms to promote } \\
\text { cross-country learning and } \\
\text { enhance sustainability }\end{array}$ & $\begin{array}{l}\text { Economic } \\
\text { Growth; } \\
\text { Food Production }\end{array}$ & 41.0 \\
\hline
\end{tabular}

Table 1 shows the specific policies, expected outcomes and related indicators for each of these improvements. The effectiveness and costs of each of these policies can be predicted from Table 1. The government can adopt nationally appropriate interventions to prevent countries from becoming more vulnerable. Table 2 shows the expected results and the degree of change in the corresponding indicator under each policy:

Table 2. Policy implementation results

\begin{tabular}{llll}
\hline Factor & Current Value & Optimal Value & $\Delta(\mathbf{\%})$ \\
\hline Government expenditure on education & 0.9663 & 1.0469 & 8.34 \\
GNI per capita & 0.0358 & 0.0386 & 7.94 \\
GDP growth rate & 0.6273 & 0.6627 & 5.65 \\
Unemployment rate & 0.8381 & 0.8865 & 5.78 \\
Tax revenue & 0.0812 & 0.0832 & 2.36 \\
Cereal yield & 0.7719 & 0.8095 & 4.87 \\
average CO2 emissions & 0.1504 & 0.1538 & 2.23 \\
Forest area & 0.6947 & 0.7132 & 2.66 \\
Improved water source & 0.6543 & 0.6731 & 2.86 \\
\hline
\end{tabular}

The implementation of the policy brings about the improvement of the national vulnerability index. Table 3-3 shows the changes in social, economic, political and climatic aspects as well as the changes in the general indicators after the implementation of the policy. The forecast results show that the total cost of interventions is about $\$ 1492.8$ million and FSI is up by $7.44 \%$. The changes of specific indicators are as follows: 
Table 3. The value of the indicator changes

\begin{tabular}{llllll}
\hline & & $\begin{array}{l}\text { Society } \\
\text { Index }\end{array}$ & $\begin{array}{l}\text { Economy } \\
\text { Index }\end{array}$ & $\begin{array}{l}\text { Politics } \\
\text { Index }\end{array}$ & $\begin{array}{l}\text { Climatic } \\
\text { Conditions }\end{array}$ \\
\hline \multirow{2}{*}{$\Delta(\%)$} & value & 2.09 & 6.45 & 1.18 & 3.16 \\
\cline { 2 - 6 } & FSI & 7.44 & & & \\
\hline
\end{tabular}

\section{Conclusions}

From the above analysis, it can be known that climate change of a country or region does have a certain degree of influence on the instability of that country or region, and the influence can be divided into direct influence and indirect influence. In other words, climate change will further affect national stability through economic, political and social factors.

Countries around the world are also actively working to reduce the adverse effects of climate change through policy instruments, including technical support in agriculture, land planning, and resource networking. It is worth noting that countries need to develop appropriate policies based on their geographical location and external circumstances.

Take the fragile states of sub-saharan Africa. First, these countries can actively cultivate and apply for the driving forces and participants that support national construction. Second, the establishment of insurance mechanisms to reduce risk volatility to bridge the gap between short-term demand and long-term policy and resilience. Then, you can also invest more on education to cultivate human and social capital. In addition, we can actively promote regional integration and strive to ensure national security. To sum up, construction and social cohesion is a long-term process, which can take various forms at any time, requiring constant attention and appropriate on-site support. Society is surrounded by the state, but the state can run through and transform social relations (Robert Schuman,2009).

\section{Further Thinking of the Model}

Although the FSI index as defined in this paper has strong universality, due to the diversity of countries, it is inevitable to apply the model to different countries. Therefore, the national conditions should be classified. Ian Bremer presents a model for a new concept country,which describes the relationship between the stability of a country and its openness, and it describes a skewed J-curve (Briand R,2006). The countries at the bottom of the curve are considered unstable and the countries in the upper part are relatively stable

Drawing on the idea of this model, this paper divides countries into four categories:

1) Closed and Vulnerable: This type of country has fewer resources, is more affected by climate, and has a weaker government capacity to solve problems. Such as the Gambia, Chad.

2) Closed and stable: This kind of country is rich in resources and strong in its ability to resist natural disasters. Such as Arab, Russia.

3) Open and stable: The country's infrastructure in this category is well established and can be rapidly adjusted after being affected by natural disasters. For example, Sweden, the United States.

4) Open and Vulnerable: The political environment in these countries is unstable and the country's vulnerability is affected by many external factors. For example, Costa Rica, Nepal. 


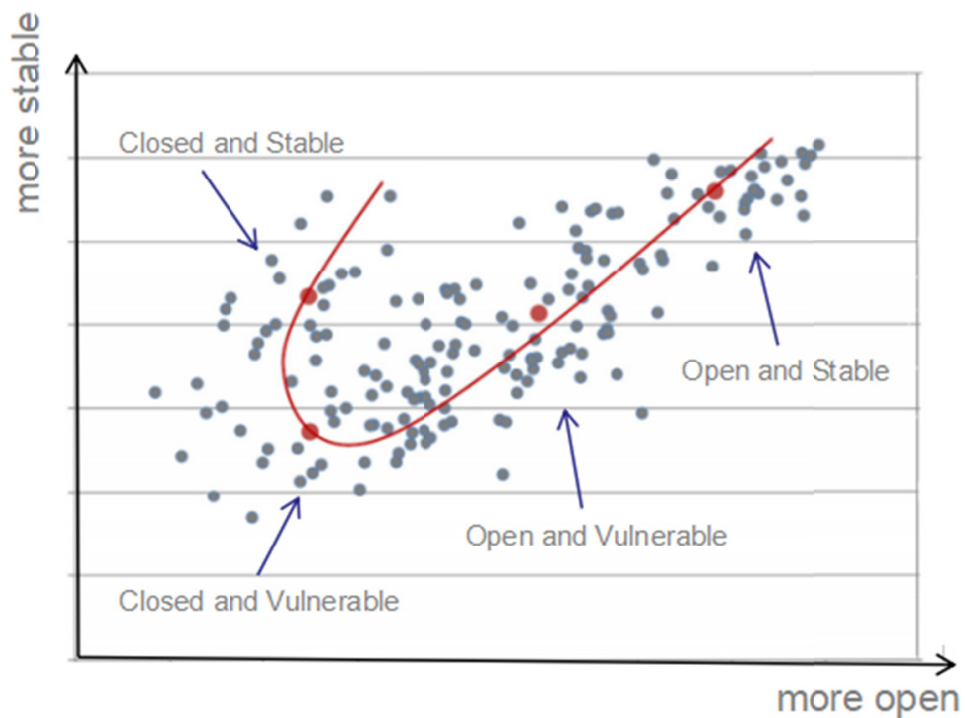

Figure 6. Country classification

Due to the different situations in different countries, the social, political, economic and climate reliance of FSI in each category of countries will also vary. In further research, we can redefine each weight according to country classification to make the model more suitable for country-specific situations. Limited to time and article length, we do not do in-depth study.

\section{References}

ACCCRN.

Retrieved

from

http://www.rockefellerfoundation.org/what-we-do/current-work/developing-climate-change-resilience/asian -cities-climate-change-resilience/

AFD.

Retrieved from

http://www.afd.fr/jahia/webdav/site/afd/shared/PORTAILS/PAYS/EUDN_INDONESIE/Fiche_AFD_CCPL eng.pdf

Bradley, D. (2007). East and Southeast Asia. Background on World Politics, 1(2), 21-23.

Briand, R. (2006). The J Curve: A New Way to Understand Why Nations Rise and Fall—by Ian Bremmer. Ethics \& International Affairs, 20(4), 537-539. https://doi.org/10.1111/j.1747-7093.2006.00053.x

CTI. Retrieved from http://www.uscti.org/uscti/default.aspx

European Report on Development. (2009). Overcoming Fragility in Africa. Retrieved from http://erd.eui.eu/erd-2009/

GEF. Retrieved from http://gefonline.org/projectDetailsSQL.cfm?projID=4340

Gourou, P. (2007). The Democratic Republic of the Congo. Africa South of the Sahara, p. 295.

Ikpe, E. (2007) Challenging the discourse on fragile states. Conflict Security \& Development, 7(1), 85-124. https://doi.org/10.1080/14678800601176543

JICA. Retrieved from http://www.mofa.go.jp/ICSFiles/afieldfile/2008/09/02/h2008_indon.pdf

Krakowka, A. R., Heimel, N., \& Galgano, F. A. (2012). Modeling Environmental Security in Sub-Saharan Africa. Geographical Bulletin, 53(1), 21-38.

Menkhaus, K. (2014). State Failure, State-Building, and Prospects for a "Functional Failed State" in Somalia. Annals of the American Academy of Political \& Social Science, 656(1), 154-172. https://doi.org/10.1177/0002716214547002

№. (2014). Fragile states index. Foreign Policy, pp. $72-77$.

Schwartz, P., \& Randall, D. (2004). An Abrupt Climate Change Scenario and its Implications for United States. National Security, 2(1). 
Theisen, O. M., Gleditsch, N. P., \& Buhaug, H. (2013). Is climate change a driver of armed conflict? Climatic Change, 117(3), 613-625. https://doi.org/10.1007/s10584-012-0649-4

\section{Copyrights}

Copyright for this article is retained by the author, with first publication rights granted to the journal.

This is an open-access article distributed under the terms and conditions of the Creative Commons Attribution license (http://creativecommons.org/licenses/by/4.0/). 